\title{
HOW THE ENVIRONMENTAL IMPACT AFFECTS THE DESIGN OF LOGISTICS NETWORKS BASED ON COST MINIMIZATION
}

B. Adenso-Díaz, S. Lozano, P. Moreno (2016) "How the environmental impact affects the design of logistics networks based on cost minimization". TRANSPORTATION RESEARCH-D, 48, 214-224

\begin{abstract}
The degree of centralization of the logistics network is one of the important strategic decisions to take. This issue has often been studied but mainly from a cost minimization focus. This research studies the influence of incorporating the environmental impact in logistics network design models, comparing the results with those obtained considering cost minimization only. A fuzzy biobjective optimization model is used to carry out a number of experiments. By weighting the relative importance of the two objectives, the differences with respect to the base cost minimization solution can be ascertained. Our results show that in general more material is moved through warehouses when the environmental impact is considered and more decentralized facilities are opened.
\end{abstract}

Keywords: logistics network; centralized and distributed supply networks; biobjective optimization 


\section{INTRODUCTION}

Economic growth and globalization have brought about a general and significant increase in the movements of goods between producers and customers, and therefore, a need to design logistics networks through which the products will flow so that this flow is as efficient as possible. This involves making many decisions, such as how many nodes (e.g. warehouses, trans-shipment points, etc.), where to locate them, how they will be connected, which customers will be allocated to which facilities, what types of vehicle will be used and, overall, how the goods will flow along the network. A poorly designed network can lead to unnecessary goods movements, duplicate/redundant facilities, delays in deliveries and a negative perception of the quality of service from the point of view of the client, making the design issue very relevant (Nozick and Turnquist, 2001).

There are different ways of approaching the design of a logistics network but its degree of centralization is usually one of the key features to determine. A centralized network presents, in principle, some advantages as regards the efficient use of the resources, including inventories and labour (Pedersen et al., 2012). This generally translates (see, for example, Abdul-Jalbara et al., 2003; Chen and Chen, 2005) into lower fixed costs and a better adjustment to demand fluctuations, since aggregate inventories allow focusing on the total demand; however, this is not always so. In some pathological cases (Chen and Lin, 1990) it can happen that networks with only one central depot incur higher costs than a two-depot network.

On the other hand, distributed networks are generally assumed to offer better customer service (since customers are closer to their assigned distribution centre) as well as lower transportation costs (see Table 1). This results in a reduction of lead times, although, again, counter-examples exist for slow moving products due to the problem of warranting full truckloads, which forces shipping to be undertaken with long intervals (Min and Donghong, 2013).

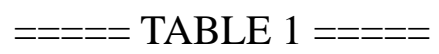


It should be noted that the advantages of each type of logistics system have usually been assessed just from the point of view of the costs incurred (resource utilization, operating costs, etc.), ignoring other criteria that can also be important for the business operations - criteria that have lately been attracting the interest of both practitioners and academics. These include issues such as the robustness of the network to guarantee a smooth and uninterrupted flow of goods (e.g. Goh et al., 2007) or, given the contribution of transportation to greenhouse gas $(\mathrm{GHG})$ emissions and the growing public concern with global warming, the environmental impact of the logistics network (e.g. Chaabane et al., 2012; Pishvaee and Razmi, 2012).

As regards the latter aspect, the alarming reports published by the scientific community have moved governments to take measures which are forcing companies to take ever more into account the environmental impact of their operations when designing new products and processes. It is therefore not surprising that, when designing the goods delivery networks and, given the impact of transportation (especially road transport) on the overall GHG emissions, companies need to consider not only cost minimization (which, according to Melo et al., 2009, represents around two thirds of total research in the area) but also environmental impact minimization (Elhedhli and Merrick, 2012), thus leading to a multiobjective approach (Bryce et al., 2014; Xifeng et al., 2013).

Regarding the economic, social and environmental performances (triple bottom line) usually attached to sustainable development, Carter and Rogers (2008) consider four supporting facets (namely, risk management, transparency, strategy and culture) in order to define the concept of Sustainable Supply Chain Management (SSCM). They claim that supply chains integrating environmental resources, in addition to knowledge and social concern, are more difficult to imitate and therefore more sustainable economically. In spite of that, some authors (e.g. Lieb and Lieb, 2010) have reported that companies are not receiving from their customers the attention that the environmental initiatives deserve.

Nevertheless, in the academic research, including the environmental factor in all the decisions along the 
supply chain, from procurement (see, for instance, Shaw et al., 2012) to all the other steps (see, for instance, Zimmer et al., 2016 for a recent review in this area), is a concern that is becoming quite common.

Abbasi and Nilsson (2016) explored the research challenges dealing with sustainability and logistics. They stressed the relevance of the study of network imbalances which reduce fill rates, meaning higher emissions volumes. These imbalances are explained by these authors as due, on occasions, to geographical location problems, which makes the research on factors affecting regional deployment, such as those considered here, especially important.

Therefore, the goal pursued here is to understand how the environmental impact of logistics operations, that in the literature is identified as a key factor in the sustainability of a company's business, can affect the regular operations in the supply chain, depending on the degree of centralization of the network, as well as on the dispersion of the customers. The results will allow us to better understand how considering the environmental factor (which eventually will be on the agenda of most companies) should impact on operations in the supply network, and thus be designed by not only taking into account cost variables.

This paper studies how including the environmental impact as an additional objective affects the optimal design of the logistics network. To that end, a general scenario of a manufacturing plant from where the goods must be delivered to customers, either directly or through intermediate warehouses, is considered. A biobjective optimization model will be used to compute the optimal network design. This allows the study of the changes in the solution, as the weight of the environmental impact objective grows with respect to that of the cost minimization objective. This comparison can shed light both on the effects and the need to incorporate this environmental impact criterion within the business decision processes.

The structure of the paper is the following. In Section 2 the scenario and network structure used in the 
experiments as well as the factors to be considered are presented. In Section 3 the corresponding biojective optimization model is formulated. Section 4 describes the generation of the problem instances and the results obtained. These results are analysed and discussed in Section 4.1. Finally, Section 5 summarizes and concludes.

\section{PROBLEM DESCRIPTION: SCENARIO AND FACTORS}

In order to address the above research question, it is necessary to define a simple scenario but of sufficient generality to be able to draw valid conclusions. Thus, let us consider a single manufacturing plant with a central location, from which goods must be distributed to clients spread across an ample surrounding region. The goods can be delivered direct from the plant (which corresponds to a centralized network solution) or through a series of regional warehouses. To increase the realism, we may assume that there is uncertainty in the demand and in the warehouse capacities, which will be assumed to be fuzzy numbers.

Transportation will be undertaken using two types of vehicle. Longo (2012) also considers two different types of vehicles in his simulation model designed to minimize the environmental impact of adding new nodes in a supply chain. Although in his case the vehicles are of a hybrid type or traditional (the former performing better from an environmental impact point of view, and the latter from the point of view of cost), we are taking only homogeneous vehicles (namely, the traditional type) for the sake of a fairer comparison: big trucks (for large deliveries, especially from the plant) or smaller vans (useful for making smaller deliveries shipped from the warehouses). The two types of vehicle have a different contribution to each of the two objective functions considered, but are always proportional to the distance travelled and the amount shipped. The two objectives are the transportation and stockholding costs on the one hand and, on the other, the GHG emissions due to the deliveries.

The manufacturing plant is assumed to have unlimited capacity so that, in principle, all clients could be directly serviced from the plant, although for small clients that option would not be attractive as it may 
negatively impact on both objective functions.

In order to study the effects of considering the environmental impact in the design of a logistics network, two experimental factors have been considered. Thus, since a key point of distribution networks is their closeness to customers, their degree of clustering (or, equivalently, the customers' dispersion) is important to consider. Therefore, if a large fraction of clients is clustered (e.g. around a certain industrial region) it would seem more natural to locate a regional warehouse within that area from which to supply them. On the other hand, if customers are more or less uniformly spread across a region then the advantages of regional warehouses are reduced. Hence, one of the factors considered when generating the problem instances relates to the dispersion of clients. This factor, labelled F1, will have two levels: clustered clients versus spread clients.

The second factor that logically affects the centralization of the network is the distance of clients from the manufacturing plant. Thus, for example, if most clients are close to the plant, then it is likely that warehouses will not be necessary. Hence, the second factor, labelled F2, relates to the closeness to the plant and also has two levels: near and far. Therefore, four different factor/level combinations will be considered in the experiments (see Figure 1).

\section{$====$ FIGURE 1 =====}

\section{MODELLING THE NETWORK CONFIGURATION}

As mentioned above, to better capture the uncertain nature of the logistics operations, we are going to consider both demand and capacity, defined through three different fuzzy numbers (see the appendix for a brief review of fuzzy numbers). By considering a fuzzy capacity, we do not mean that the capacity is considered random by the company. What we aim to do is try to capture the fact that the capacity of a warehouse is not an absolutely fixed number, and it is always possible to store a little bit more if necessary (or perhaps the capacity may be smaller, for whatever reason). 
First, the demand $\mathbf{D}_{i}$ of each customer $i \in \mathrm{I}$ is defined as a triangular fuzzy number with a membership function defined by $\left(\mathrm{D}^{-}, \mathrm{D}^{\mathrm{O}}{ }_{i}, \mathrm{D}^{+}{ }_{i}\right)$; the upper limit of the capacity of warehouse $i \in \mathrm{J}$ is defined by a fuzzy number with a linear decreasing membership function given by parameters $\left(\mathrm{U}_{j}^{-}, \mathrm{U}^{+}{ }_{j}\right)$, while the lower limit of the warehouse capacity (below which the warehouse should not be open for economic reasons) is a fuzzy number with a linear increasing membership function given by parameters $\left(\mathrm{L}_{j}^{-}, \mathrm{L}^{+}{ }_{j}\right)$.

\section{TABLE 2 =====}

All the other data will be crisp values, including: distances, unit GHG emissions and unit transportation costs (between warehouses and customers, between central plant and customers, and between central plant and warehouses), as well as the fixed cost of using a warehouse. Table 2 summarizes the notation used. Regarding the decision variables, the goods delivered to each client must come from the central plant or from a warehouse, therefore variables $\mathrm{x}_{i j}$ and $\mathrm{x}^{\prime}{ }_{i}$ respectively will capture these amounts. Note that it is not necessary to define variables for the units transported from the central plant to warehouses since every unit leaving a warehouse has to have been received previously from the central plant. We assume that not all the customers can be served from warehouse $j$, due to distance constraints. Thus, let $\mathrm{I}(\mathrm{j})$ be the set of customers that can be served from warehouse $j$.

In order to determine the best solution (flows and warehouses that are open), given a specific instance, a model based on Garcia-Carbajal et al. (2015) will be used. Since we have two objectives to study (cost and impact) we shall consider a fuzzy biobjective approach, see [1]-[5], whose constraints will guarantee that the customers' demands are covered via a warehouse or direct from the plant, and that the flow from each warehouse fulfils its upper and lower bounds:

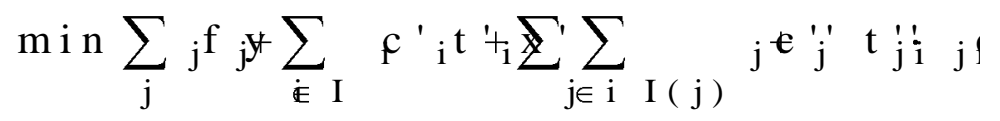




$$
\min \sum_{i \in I} e^{\prime}{ }_{i} t^{\prime}+x \sum_{j \in i} \sum_{I(j)} j e+t^{\prime} t^{\prime} j^{\prime} i \cdot j e
$$

s.t.

$$
\begin{gathered}
x_{i}^{\prime}+\sum_{j: i \in I(j)} x_{j i}=\bar{D}_{i} \quad \forall i \in I \\
\bar{L}_{j} y_{j} \leq \sum_{i \in I(j)} x_{j i} \leq \bar{U}_{j} y_{j} \quad \forall i \in I \\
x_{j}^{\prime}, x_{j i} \geq 0, y_{j} \text { binary }, \bar{D}_{i}, \bar{L}_{j}, \bar{U}_{j} \quad \text { fuzzy numbers }
\end{gathered}
$$

To solve this biojective fuzzy model, we use the Tiwari et al. (1987) additive approach, consisting of maximizing the (weighted) sum of the membership functions of both objectives, defined by appropriate linear decreasing functions from their lowest to their highest values $\left(\mathrm{C}^{-}\right.$and $\mathrm{C}^{+}$for costs; $\mathrm{E}^{-}$and $\mathrm{E}^{+}$for emissions, see Figure 2).

\section{FIGURE 2 =====}

To do so, it is necessary to calculate the extreme values of each objective function for each instance to be solved. For the extreme cost value $\mathrm{C}^{-}\left(\right.$resp. $\left.\mathrm{C}^{+}\right)$, this is done by minimizing (resp. maximizing) objective function [1] subject to [3]-[5] using a fixed demand value $\mathrm{D}_{i}=\mathrm{D}_{i}^{-}\left(\right.$resp. $\mathrm{D}^{+}{ }_{i}$ ), and fixed capacity limits $\mathrm{U}_{j}=\mathrm{U}_{j}^{+}$and $\mathrm{L}_{j}=\mathrm{L}_{j}^{-}$. The extreme emissions value $\mathrm{E}^{-}$(resp. $\mathrm{E}^{+}$) is computed analogously but minimizing (resp. maximizing) objective function [2].

Although by using the Tiwari et al. (1987) additive model, we shall not consider both objectives to be equally important, we shall analyse how the result varies as the importance of the emissions increases. Therefore, our weighted objective function will be:

$$
\max \lambda_{1}+\beta \lambda_{2}
$$

with $\beta \geq 0$ indicating the weight of the GHG emissions objective. Note that $\beta=0$ represents the classical 
case of minimizing only costs.

Regarding the constraints of the crisp model, they are [7]-[15] plus [5]:

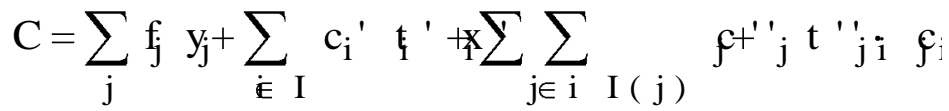

$$
\begin{aligned}
& E=\sum_{i \in I} e_{i}{ }^{\prime} t^{\prime} \sum_{j \in i} \sum_{I(j)} \rho^{\prime \prime}{ }_{j} t^{\prime \prime}{ }_{j i} \cdot e_{i} \\
& \lambda_{1}=\frac{\mathrm{C}^{+}-\mathrm{C}}{\mathrm{C}^{+}-\mathrm{C}^{-}} \\
& \lambda_{2}=\frac{\mathrm{E}^{+}-\mathrm{E}}{\mathrm{E}^{+}-\mathrm{E}^{-}} \\
& \mathrm{D}_{\mathrm{i}}^{+}+\mu \cdot\left(\mathrm{D}_{\mathrm{i}}^{0}-\mathrm{D}_{\mathrm{i}}^{-}\right) \leq \mathrm{x}_{\mathrm{i}}^{\prime}+\sum_{\mathrm{j} \mathrm{i} \in \mathrm{I}(\mathrm{j})} \mathrm{x}_{\mathrm{ji}} \leq \mathrm{D}_{\mathrm{i}}^{+}-\mu \cdot\left(\mathrm{D}_{\mathrm{i}}^{+}-\mathrm{D}_{\mathrm{i}}^{0}\right) \quad \forall \mathrm{i} \\
& \mu \leq \frac{U_{j}^{+}-\sum_{i \in I(j)} x_{j i}}{U_{j}^{+}-U_{j}^{-}}+\left(1-y_{j}\right) \quad \forall j \\
& \mu \leq \frac{\sum_{i \in I(j)} x_{j ~ i}{ }^{-L^{-}} j}{L_{j}^{+}-L_{j}^{-}}+\left(1-y_{j}\right) \cdot\left(1+\frac{L^{-} j}{L^{+}{ }_{j}^{-} L^{-}}\right) \quad \forall j \\
& L_{j}^{-} y_{j} \leq \sum_{i \in I(j)} x_{j}\left\{\quad U_{j} y_{j} \forall\right. \\
& \left.\mathrm{x}_{\mathrm{i}}^{\prime}, \mathrm{x}_{\mathrm{i}} \geq \boldsymbol{Q} ; \boldsymbol{\lambda}, \overline{2} \quad\left[\boldsymbol{\mu}, 1 \boldsymbol{1} \boldsymbol{\mu} ; \mathrm{mi}_{\mathrm{i}} \in,\right\}\right] \text {; }
\end{aligned}
$$

Constraints [7] and [8] evaluate the costs and emissions, given the values of the decision variables; the 
definitions of $\lambda_{1}$ and $\lambda_{2}$, as per Figure 2, are given by [9]-[10]; fuzzy constraint [3] is translated into [11], introducing a new parameter $\mu$ so that the demand is exactly equal to $\mathrm{D}^{0}$ when $\mu=1$ and between $\mathrm{D}^{-}$and $\mathrm{D}^{+}$for $\mu=0$. Constraint [15] imposes that this demand membership value should be higher than a lower bound $\mu_{\min }($ Chen and Tsai, 2001).

The left part of fuzzy constraint [4] is translated in our crisp model into [12] (only active when $\mathrm{y}_{\mathrm{j}}=1$ ) while the right part is captured by [13] (also only active when $y_{j}=1$ ). Note that, both in constraints [12] and [13] the same value of $\mu$ as in [11] is used, thus defining a uniform membership level for all customers and all warehouses. Finally [14] forces the maximum and minimum capacities of a warehouse never to be exceeded.

\section{EXPERIMENTAL FRAMEWOK AND RESULTS}

For performing the required experiments, a set of instances were generated. These instances are defined over a grid of $1000 \times 1000 \mathrm{~km}^{2}$ with 80 potential positions for the warehouses, and always reserving the central position for the central plant (see Figure 3). In each instance 400 customers are randomly located according to the two bi-level factors previously mentioned (clustered/spread; close/far). Thus, when for instance a clustered instance is to be generated, firstly five warehouses are randomly selected in the grid and $90 \%$ of all the customers are randomly generated around them, with the other $10 \%$ of customers randomly located at any point in the grid. A total of 50 instances are generated for each of the four combinations of the two factors F1 and F2, which means 200 instances in total.

\section{$=====$ FIGURE 3 =====}

In each case, distances are calculated using the Euclidean metric, and sets $I(j)$ are defined by a radius of $200 \mathrm{~km}$ from each warehouse. For determining the customer demand, the nominal value $\mathrm{D}_{i}^{0}$ is uniformly generated around some predefined values, leading to the upper and lower values $\mathrm{D}_{i}^{+}$and $\mathrm{D}_{i}^{-}$, calculated as $\pm 20 \%$ of the nominal value. When the weekly demand is greater than 15 tons, a large truck is assigned. 
For the two types of vehicles (trucks and vans) cost and emission factors are shown in Table 3 and include the corresponding corrections to deal with non-full truckloads. The emission factors used correspond to those computed by the LIPASTO model developed by the Technical Research Centre of Finland, VTT (http://lipasto.vtt.fi/yksikkopaastot/tavaraliikennee/tieliikennee/tavara_tiee.htm). Costs were assigned using current prices from a Spanish carrier.

$=====$ TABLE 3 =====

Regarding how to measure the level of decentralization in a network, it is to be expected that a higher centralization level implies that the number of open warehouses increases as well as the material reaching the customers through them. Therefore, each of the 200 instances considered is solved using models [5]-[15] for different $\beta \geq 0$ values, and two output variables are recorded, namely the number of open warehouses in the optimal solution and the percentage of material served from the open warehouses, measured according to the formula:

$$
\frac{\sum_{j} \sum_{i \in I(j)} x_{j i}}{\sum_{j} \sum_{i \in I(j)} x_{j i}+\sum_{i} \hat{x}_{i}}
$$

Comparing these outputs for different values of parameter $\beta$, we can compare the results when only costs are considered $(\beta=0)$ and when the weight of the environmental impact increases in its importance.

$$
=====\text { FIGURE } 4 \text { ===== }
$$

\subsection{Results}

All the 200 instances were initially solved for nine different values $\beta \in\{0 ; 0.5 ; 1 ; \ldots ; 3.5 ; 4\}$, and for each solution (see an example in Figure 4) both output metrics were recorded. Note that we are considering some rather extreme $\beta$ values (a case with $\beta=4$ assigning four times more importance to the 
environmental impact than to the cost is not realistic) in order to obtain an asymptotic overall vision of the results.

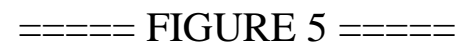

Figure 5 represents the percentage of material moved via the warehouses for the four levels of the two factors considered, and for the extreme values $(\beta=0$ and $\beta=4)$ of the weight of the environmental impact objective. It can be seen that the amount of material going through the warehouses does not depend on the level of clusterization of the customers, although some degree of economies of scale could be expected when the customers are close.

However, regarding F2, it seems that there is a difference between its two levels: when the customers are far from the central plant more material is sent using regional facilities. As $\beta$ increases, the effects are the same although always with a higher percentage of material sent via warehouses. The numerical results are shown in Table 4.

\section{$=====$ TABLES 4,5 =====}

Regarding the number of open warehouses, Table 5 shows the average value of this output for the different factor levels and factor level combinations. Again, a more decentralized logistics network is preferred when customers are not clustered or are far from the plant, and more warehouses are always opened when more weight is given to the environmental impact (see Figure 6). However, only in the case of F1 does a significant difference between its two levels seem to exist, with a clearly higher number of warehouses open when customers are spread out. An interaction between both factors was observed (clearly increasing the number of open warehouses in the case of far non-clustered clients) with the interaction increasing with $\beta$.

$====$ FIGURE 6 ===== 
To answer the main research question, i.e., whether the two metrics considered are affected by the value of $\beta$, unfortunately we cannot use any parametric test due to the lack of normality. We have considered the paired Wilcoxon Signed-Rank test in order to compare the results for the weighted objective functions solutions with the baseline case $\beta=0$ (i.e., only cost minimization as the objective function).

Regarding the percentage of material moved through warehouses, the null hypothesis $\mathrm{H} 0[\operatorname{median}(\beta=0)$-median $(\beta)=0]$ was rejected in every case except $\beta=0.5$ (i.e., cost is more important than environmental impact) which had an associated p-value of 0.27 . Therefore, as the environment impact becomes important, the percentage of material decentralized is different from the percentage considering only the cost. Testing the null hypothesis $\mathrm{H} 0[\operatorname{median}(\beta=0)$-median $(\beta) \leq 0]$ for $\beta>0.5$ it was found that it is never rejected, thus confirming that when only cost is considered in the objective function less material is moved through warehouses.

In relation to the number of open warehouses, a similar test rejects, for all the $\beta>0$, that the number is the same as with $\beta=0$; a further analysis shows that in all cases ( $\mathrm{p}$-value $\approx 1.0$ ), more warehouses are open when considering the environmental impact than when considering only the cost. However, this result is mainly due to the assumption of no fixed carbon emissions of open warehouses. This assumption corresponds to the case in which the carbon emissions due to setting up and operating a warehouse are negligible when compared with the carbon emissions due to transportation. Should that not be the case, then the proposed model can easily incorporate such fixed carbon emissions charges in objective function (2). Although that would make the two objective functions have a similar structure that does not mean they have to be aligned and that trade-offs between cost and carbon emissions do not occur. Such trade-offs are a key feature of the proposed approach.

A further McNemar test confirms these results regarding both the material moved and the warehouses opened. However, given the observed difference regarding the percentage of material moved through 
warehouses when we consider values of $\beta$ smaller than 1.0, and in order to focus on that region, additional experiments were carried out using, in this second round of experiments, only moderate values of $\beta$, specifically $\beta=\{0.0 ; 0.1 ; 0.2 ; \ldots ; 1.0\}$. Again the paired Wilcoxon Signed-Rank test confirms the results previously obtained (see Table 6). The null hypothesis $H 0[\operatorname{median}(\beta=0)$-median $(\beta)=0]$ was rejected for $\beta \geq 0.6$, indicating that only when the environmental objective is given sufficient importance does its consideration have an effect in determining the optimal solution and this translates into an increased use of regional warehouses. For values of $\beta<0.6$ the environmental impact objective does not have a significant effect on the degree of decentralization of the material flow.

This can also be seen in Figure 7, which shows the amount of material moved through warehouses as a function of the importance given to the cost. In general, the higher the importance of the environmental impact, the more material is moved through warehouses. As regards the number of warehouses open, it can be seen that more facilities start opening as soon as the environmental impact is included in the objective function (i.e., $\forall \beta>0$ ).

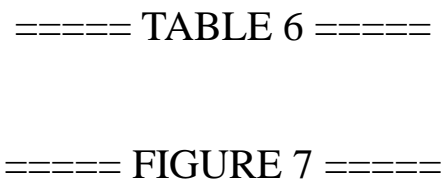

Summarizing the experimental results, it has been found that the supply network design and product flow is sensitive to the consideration of environmental impacts in conjunction with total cost. Thus, the larger the weight given to carbon emissions the larger the incentive to take advantage of "economies of scale" (in terms of emissions) that represent shipping to warehouses, as opposed to shipping direct to customers. This leads to opening more warehouses and sending more units through these warehouses. The resulting increased decentralization of the supply chain, ultimately, is a consequence of the trade-offs between cost and environmental impact when the latter is emphasized. This effect, however, is mediated by the clustering and proximity factors, so that geographical distance positively affects the percentage of 
material moved through the warehouses while customer dispersion positively affects the number of warehouses used.

\section{CONCLUSIONS}

This paper has studied the effects of considering the environmental impact (in addition to the usual cost criteria) in the design of a logistics network. To that end a biobjective optimization model that takes into account uncertainty in the demand and in the warehouse capacities has been used. Different transport vehicles can be used, depending on the amount to be shipped and the distance travelled. The two objective functions have been aggregated using a weighting factor that represents the importance given to the environmental impact (i.e., GHG emissions) criterion. A simple experimental design with two factors (namely, degree of clustering of customers and level of proximity of customers to manufacturing plant) has been considered and 200 instances have been randomly generated and solved for different values of the environmental impact weight.

Two aspects of the solutions obtained have been considered to analyse the results. These two output metrics are related to the degree of centralization of the network. One is the number of warehouses open in the optimal solution; the other is the percentage of goods delivered through the warehouse (as opposed to being shipped direct from the manufacturing plant).

It has been found that a more decentralized logistics network is preferred when customers are far from the plant and are not clustered, and it is always the case that more warehouses are opened when more weight is given to the environmental impact of the operations.

As regards the percentage of goods delivered, the results show that more material is moved through the warehouses when the environmental impact increases its importance in the objective function beyond a threshold of around $50 \%$ of the weight of the cost objective. Any weight given to the environmental 
impact also makes the number of warehouses opened increase significantly.

Although the results obtained are relevant for managers and suggest that incorporating environmental impacts in the design of logistics networks can have an influence on the degree of centralization of the network and how the material flows, it must, however, be considered that the present study has a number of limitations. Thus, for example, a static approach and a single manufacturing plant have been assumed; two types of vehicle and specific assignment rules to them have also been assumed. Moreover, specific membership functions for the demand and the warehouse capacities have been assumed. In a real setting, all these parameters and the model should be adjusted to the scenario at hand. In any case, more research on this issue may be necessary to confirm the obtained results.

Acknowledgement.- Research funded by the Spanish Ministry of Science, grant DPI2013-41469-P, and the European Regional Development Fund (ERDF).

\section{APPENDIX}

In this appendix a brief review of fuzzy sets and fuzzy numbers is presented. Thus, a fuzzy set $\bar{X}$ in an universe of discourse $\mathrm{X}$ is characterized by a membership function $\mu_{\bar{X}}(x)$ which to each element $\mathrm{x} \in \mathrm{X}$ associates a real number in the interval 0,1 . A fuzzy set $\bar{X}$ is a normal fuzzy set if $\exists x \in X: \mu_{\bar{X}}(x)=1$. On the other hand, a fuzzy set $\bar{X}$ is convex if, and only if, $\forall x, x^{\prime} \in X, \forall \lambda \in[0,1]: \mu_{\bar{X}}\left(\lambda x+(1-\lambda) x^{\prime} \geq \min \left\{\mu_{\bar{X}}(x) ; \mu_{\bar{X}}\left(x^{\prime}\right)\right\}\right.$.

A fuzzy number is a fuzzy set that is both normal and convex. The most commonly used types of fuzzy numbers are triangular and trapezoidal. A triangular fuzzy number (TFN) can be defined by a triplet $\mathrm{x}_{1}, \mathrm{x}_{2}, \mathrm{x}_{3}$ with an associated membership function. 
$\mu_{\bar{X}}(x)=\left\{\begin{array}{lc}0 & \text { if } \mathrm{x} \leq \mathrm{x}_{1} \text { or } \mathrm{x} \geq \mathrm{x}_{3} \\ \frac{x-x_{1}}{x_{2}-x_{1}} & \text { if } \mathrm{x}_{1} \leq \mathrm{x} \leq \mathrm{x}_{2} \\ \frac{x-x_{3}}{x_{2}-x_{3}} & \text { if } \mathrm{x}_{2} \leq \mathrm{x} \leq \mathrm{x}_{3}\end{array}\right.$

Likewise, a trapezoidal fuzzy number $(\operatorname{TrFN})$ can be defined by a 4-tuple $\mathrm{x}_{1}, \mathrm{x}_{2}, \mathrm{x}_{3}, \mathrm{x}_{4}$ with an associated membership function

$\mu_{\bar{X}}(x)=\left\{\begin{array}{lc}0 & \text { if } \mathrm{x} \leq \mathrm{x}_{1} \text { or } \mathrm{x} \geq \mathrm{x}_{4} \\ \frac{x-x_{1}}{x_{2}-x_{1}} & \text { if } \mathrm{x}_{1} \leq \mathrm{x} \leq \mathrm{x}_{2} \\ 1 & \text { if } \mathrm{x}_{2} \leq \mathrm{x} \leq \mathrm{x}_{3} \\ \frac{x-x_{4}}{x_{3}-x_{4}} & \text { if } \mathrm{x}_{3} \leq \mathrm{x} \leq \mathrm{x}_{4}\end{array}\right.$

It is clear that TFNs are a subclass of TrFNs, namely those TrFNs for which $x_{2}=x_{3}$.

An alternative, equivalent way of defining a TFN is as a triplet $x_{1}, a, b$ such that the corresponding membership function is

$\mu_{\bar{X}}(x)=\left\{\begin{array}{lc}0 \quad \text { if } \mathrm{x} \leq \mathrm{x}_{1}-\text { a or } \mathrm{x} \geq \mathrm{x}_{1}+b \\ \frac{x-x_{1}+a}{a} & \text { if } \mathrm{x}_{1}-a \leq \mathrm{x} \leq \mathrm{x}_{1} \\ \frac{x_{1}+b-x}{b} & \text { if } \mathrm{x}_{1} \leq \mathrm{x} \leq \mathrm{x}_{1}+b\end{array}\right.$

Analogously, a trapezoidal fuzzy number (TrFN) can be defined by a 4-tuple $\mathrm{x}_{1}, \mathrm{x}_{2}, \mathrm{a}, \mathrm{b}$ with an associated membership function 
$\mu_{\bar{x}}(x)=\left\{\begin{array}{lc}0 \quad \text { if } \mathrm{x} \leq \mathrm{x}_{1}-\text { a or } \mathrm{x} \geq \mathrm{x}_{2}+b \\ \frac{x-x_{1}+a}{a} & \text { if } \mathrm{x}_{1}-a \leq \mathrm{x} \leq \mathrm{x}_{1} \\ 1 & \text { if } \mathrm{x}_{1} \leq \mathrm{x} \leq \mathrm{x}_{2} \\ \frac{x_{2}+b-x}{b} & \text { if } \mathrm{x}_{2} \leq \mathrm{x} \leq \mathrm{x}_{2}+b\end{array}\right.$

In this alternative representation, TFNs are still a subclass of TrFNs, namely those TrFNs for which $\mathrm{x}_{1}=\mathrm{x}_{2} \cdot$

\section{REFERENCES}

Abbasi, M. and Nilsson, F. Developing environmentally sustainable logistics. Exploring themes and challenges from a logistics service providers' perspective. Transportation Research Part D, $46,273-283(2016)$

Abdul-Jalbara, B., Gutiérrez, J., Puerto, J. and Sicilia, J. Policies for inventory/distribution: The effect of centralization versus decentralization. International Journal of Production Economics. 81-82, 281-293 (2003)

Bryce, J.M., Flintsch, G. and Hall, R.P. A multi criteria decision analysis technique for including environmental impacts in sustainable infrastructure management business practices. Transportation Research Part D, 32 (1), 435-445 (2014)

Carter, C.R. and Rogers, D.S. A framework of sustainable supply chain management: Moving toward new theory. International Journal of Physical Distribution and Logistics Management, 38 (5), 360-387 (2008) 
Chaabane, A., Ramudhin, A. and Paquet, M. Design of sustainable supply chains under the emission trading scheme. International Journal of Production Economics. 135 (1), $37-49$ (2012)

Chen, J.-M. and Chen, T.-H. The multi-item replenishment problem in a two-echelon supply chain: the effect of centralization versus decentralization. Computers and Operational Research. 32, 3191-3207 (2005)

Chen, L.H. and Tsai, F.C. Fuzzy goal programming with different importance and priorities. European Journal of Operational Research, 133, 548-556 (2001)

Chen, M.-S. and Lin, C.-T. An example of disbenefits of centralized stocking. Journal of the Operational Research Society, 41, 259-262 (1990)

Elhedhli, S. and Merrick, R. Green supply chain network design to reduce carbon emissions. Transportation Research Part D, 17 (5), 370-379 (2012)

García-Carbajal, S., Palacio, A., Adenso-Díaz, B. and Lozano, S. "Fuzzy bicriteria optimization approach to distribution network design," in Recent Advances in Computational Optimization. S. Fidanova, (Ed.), Springer International Publishing, Switzerland (2015) pp. 21-33.

Goh, M., Lim, J.Y.S. and Meng, F. A stochastic model for risk management in global supply chain networks. European Journal of Operational Research. 182, 164-173 (2007)

Lieb, K.J. and Lieb, R.C. Environmental sustainability in the third-party logistics (3PL) industry. International Journal of Physical Distribution and Logistics Management, 40 (7), 524-533 (2010) 
Longo, F. Sustainable supply chain design: An application example in local business retail. Simulation, 88 (12), 1484-1498 (2012)

Melo, M.T., Nickel, S. and Saldanha-da-Gama, F. Facility location and supply chain management: a review. European Journal of Operational Research. 196, 401-412 (2009)

Min, F. and Donghong, L. Effect of warehouse centralization on lead times, IEEE 6th Int. Conf. on Information Management, Innovation Management and Industrial Engineering, Xian, China, 2013

Nozick, L.K. and Turnquist, M.A. Inventory, transportation, service quality and the location of distribution centers. European Journal of Operational Research, 129, 362-371 (2001)

Pedersen, S.G., Zachariassen, F. and Arlbjorn, J.S. Centralisation versus de-centralisation of warehousing: a small and medium-sized enterprise perspective. Journal of Small Business Enterprise Development. 19 (2), 352-369 (2012)

Pishvaee, M.S. and Razmi, J. Environmental supply chain network design using multi-objective fuzzy mathematical programming. Applied Mathematical Modelling. 36, 3433-3446 (2012)

Shaw, K., Shankar, R., Yadav, S.S. and Thakur, L.S. Supplier selection using fuzzy AHP and fuzzy multi-objective linear programming for developing low carbon supply chain. Expert Systems with Applications, 39 (9), 8182-8192 (2012)

Tiwari, R.N., Dharmar, S. and Rao, J.R. Fuzzy goal programming - an additive model. Fuzzy Sets and 
Systems, 24, 27-34 (1987)

Xifeng, T., Ji, Z. and Peng, X. A multi-objective optimization model for sustainable logistics facility location. Transportation Research Part D, 22, 45-48 (2013)

Zimmer, K., Fröhling, M. and Schultmann, F. Sustainable supplier management - A review of models supporting sustainable supplier selection, monitoring and development. International Journal of Production Research. 54 (5), 1412-1442 (2016) 


\begin{tabular}{|l|l|}
\hline \multicolumn{1}{|c|}{ Centralized } & \multicolumn{1}{|c|}{ Decentralized } \\
\hline - Number of employees & • Time to reach the client \\
- Reduced learning costs & • Better service level \\
- Less tied-up capital & • Smaller costs of lost sales \\
- Reduced fixed warehousing costs & • Local exposure \\
- Lower stock level (according to square root law) & • Reduced transportation costs \\
- Balanced peaks of demand & \\
\hline
\end{tabular}

Table 1. Main advantages of centralized versus decentralized networks.

\begin{tabular}{|l|l|}
\hline Symbol & \multicolumn{1}{|c|}{ Meaning } \\
\hline $\mathrm{t}_{j i}$ & Transportation distance $(\mathrm{km})$ from warehouse $j$ to client $i$ \\
\hline $\mathrm{t}^{\prime}{ }_{i}$ & Transportation distance $(\mathrm{km})$ from central plant to client $i$ \\
\hline $\mathrm{t}^{\prime}{ }_{j}$ & Transportation distance $(\mathrm{km})$ from central plant to warehouse $j$ \\
\hline $\mathrm{c}_{j i}$ & Transportation cost $(€ / \mathrm{km} /$ unit) from warehouse $j$ to client $i$ \\
\hline $\mathrm{c}^{\prime}{ }_{i}$ & Transportation cost $(€ / \mathrm{km} /$ unit) from central plant to client $i$ \\
\hline $\mathrm{c}^{\prime}{ }_{j}$ & Transportation cost $(€ / \mathrm{km} / \mathrm{unit})$ from central plant to warehouse $j$ \\
\hline $\mathrm{e}_{j i}$ & Transportation emissions $(\mathrm{GHG} / \mathrm{km} / \mathrm{unit})$ from warehouse $j$ to client $i$ \\
\hline $\mathrm{e}^{\prime}{ }_{i}$ & Transportation emissions (GHG/km/unit) from central plant to client $i$ \\
\hline $\mathrm{e}^{\prime}{ }_{j}$ & Transportation emissions (GHG/km/unit) from central plant to warehouse $j$ \\
\hline $\mathrm{f}_{j}$ & Fixed cost of using warehouse $j$ \\
\hline $\mathrm{x}_{i j}$ & Units to be shipped from warehouse $j$ to client $i$ \\
\hline $\mathrm{x}^{\prime}{ }_{i}$ & Units to be shipped direct from central plant to client $i$ \\
\hline $\mathrm{y}_{j}$ & Units to be shipped from central plant to warehouse $j$ \\
\hline
\end{tabular}

Table 2. Crisp data used in the model and decision variables 


\begin{tabular}{|c|c|c|c|c|}
\hline & Truck & Van & $\begin{array}{c}\text { Non-full truck, from } \\
\text { central depot, }>125 \mathrm{~km}\end{array}$ & $\begin{array}{c}\text { From warehouse, } \\
>125 \mathrm{~km}\end{array}$ \\
\hline $\mathrm{c}_{\mathrm{ji}}$ & $0.00004 € / \mathrm{kg} / \mathrm{km}$ & $0.00030 € / \mathrm{kg} / \mathrm{km}$ & & $0.00045 € / \mathrm{kg} / \mathrm{km}$ \\
\hline$\hat{\mathrm{c}}_{\mathrm{i}}$ & $0.00004 € / \mathrm{kg} / \mathrm{km}$ & $0.00030 € / \mathrm{kg} / \mathrm{km}$ & $0.00006 € / \mathrm{kg} / \mathrm{km}$ & \\
\hline$\hat{\mathrm{c}}_{\mathrm{j}}$ & $0.00004 € / \mathrm{kg} / \mathrm{km}$ & $0.00030 € / \mathrm{kg} / \mathrm{km}$ & & \\
\hline $\mathrm{e}_{\mathrm{ji}}$ & $0.0621 \mathrm{gr} \mathrm{Eq}-\mathrm{CO}_{2} / \mathrm{kg} / \mathrm{km}$ & $0.0950 \mathrm{gr} \mathrm{Eq}-\mathrm{CO}_{2} / \mathrm{kg} / \mathrm{km}$ & & $0.1425 \mathrm{gr} \mathrm{Eq}-\mathrm{CO}_{2} / \mathrm{kg} / \mathrm{km}$ \\
\hline$\hat{\mathrm{e}}_{\mathrm{i}}$ & $0.0621 \mathrm{gr} \mathrm{Eq}-\mathrm{CO}_{2} / \mathrm{kg} / \mathrm{km}$ & $0.0950 \mathrm{gr} \mathrm{Eq}-\mathrm{CO}_{2} / \mathrm{kg} / \mathrm{km}$ & $0.1425 \mathrm{gr} \mathrm{Eq}-\mathrm{CO}_{2} / \mathrm{kg} / \mathrm{km}$ & \\
\hline$\hat{\mathrm{e}}_{\mathrm{j}}$ & $0.0621 \mathrm{gr} \mathrm{Eq}-\mathrm{CO}_{2} / \mathrm{kg} / \mathrm{km}$ & $0.0950 \mathrm{gr} \mathrm{Eq}-\mathrm{CO}_{2} / \mathrm{kg} / \mathrm{km}$ & & \\
\hline
\end{tabular}

Table 3. Costs and emissions of trucks and vans depending on distance and load

\begin{tabular}{|c|c|c|}
\hline & $\begin{array}{l}\text { \% material }(\beta=0) \\
\text { (overall: } 0.7989)\end{array}$ & $\begin{array}{l}\% \text { material }(\beta=4) \\
\text { (overall: } 0.8673)\end{array}$ \\
\hline F1.1 & 0.7615 & 0.8655 \\
\hline $\mathrm{F} 1.2$ & 0.8363 & 0.8690 \\
\hline $\mathrm{F} 2.1$ & 0.7446 & 0.8283 \\
\hline $\mathrm{F} 2.2$ & 0.8532 & 0.9063 \\
\hline $\mathrm{F} 1.1 \times \mathrm{F} 2.1$ & 0.6965 & 0.8453 \\
\hline $\mathrm{F} 1.1 \times \mathrm{F} 2.2$ & 0.8265 & 0.8857 \\
\hline $\mathrm{F} 1.2 \times \mathrm{F} 2.1$ & 0.7928 & 0.8112 \\
\hline $\mathrm{F} 1.2 \times \mathrm{F} 2.2$ & 0.8799 & 0.9268 \\
\hline
\end{tabular}

Table 4. Average amount of material moved through warehouses, depending on the two factors considered, for the extreme $\beta$ values 


\begin{tabular}{|c|c|c|}
\hline & $\begin{array}{c}\text { Open wareh. }(\beta=0) \\
\text { (overall: } 3.59)\end{array}$ & $\begin{array}{c}\text { Open wareh. }(\beta=4) \\
\text { (overall: } 4.31)\end{array}$ \\
\hline F1.1 & 3.64 & 5.79 \\
\hline F1. 2 & 7.35 & 10.83 \\
\hline F2.1 & 4.96 & 6.92 \\
\hline F2. 2 & 6.03 & 9.70 \\
\hline $\mathrm{F} 1.1 \times \mathrm{F} 2.1$ & 3.30 & 5.82 \\
\hline $\mathrm{F} 1.1 \times \mathrm{F} 2.2$ & 3.98 & 5.76 \\
\hline $\mathrm{F} 1.2 \times \mathrm{F} 2.1$ & 6.62 & 8.02 \\
\hline $\mathrm{F} 1.2 \times \mathrm{F} 2.2$ & 8.08 & 13.64 \\
\hline
\end{tabular}

Table 5. Average number of warehouses open (maximum possible is five), depending on the two factors considered, for the extreme $\beta$ values

\begin{tabular}{|c|c|}
\hline$\beta$ & $p$-value \\
\hline 0.1 & 0.2105 \\
\hline 0.2 & 0.2817 \\
\hline 0.3 & 0.7083 \\
\hline 0.4 & 0.9294 \\
\hline 0.5 & 0.2746 \\
\hline 0.6 & 0.0017 \\
\hline 0.7 & 0.0003 \\
\hline 0.8 & 0.0000 \\
\hline 0.9 & 0.0000 \\
\hline 1.0 & 0.0000 \\
\hline
\end{tabular}

Table 6. p-values for the Wilcoxon Signed-Rank test for the percentage of material moved when $\beta=0$ as compared with $\beta=0.1 ; . . ; 1.0$. 

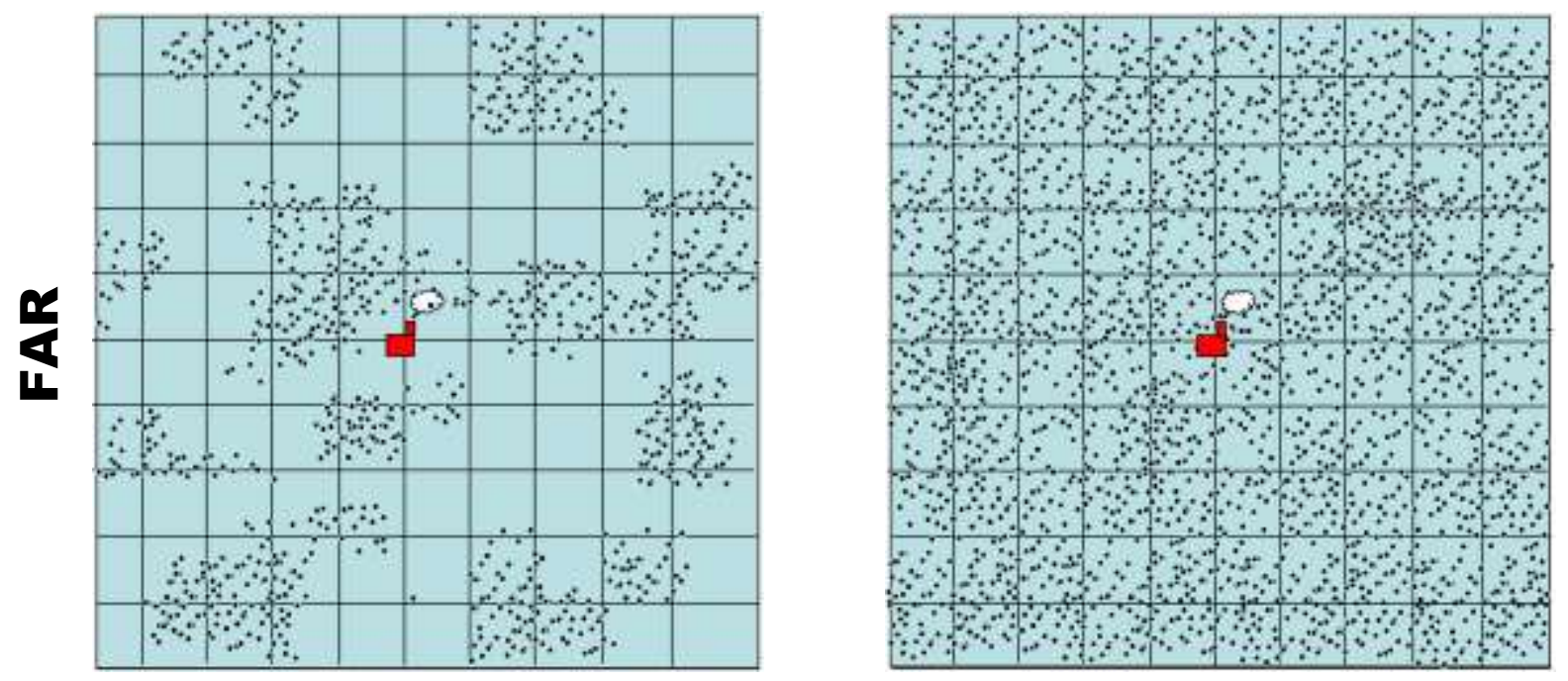

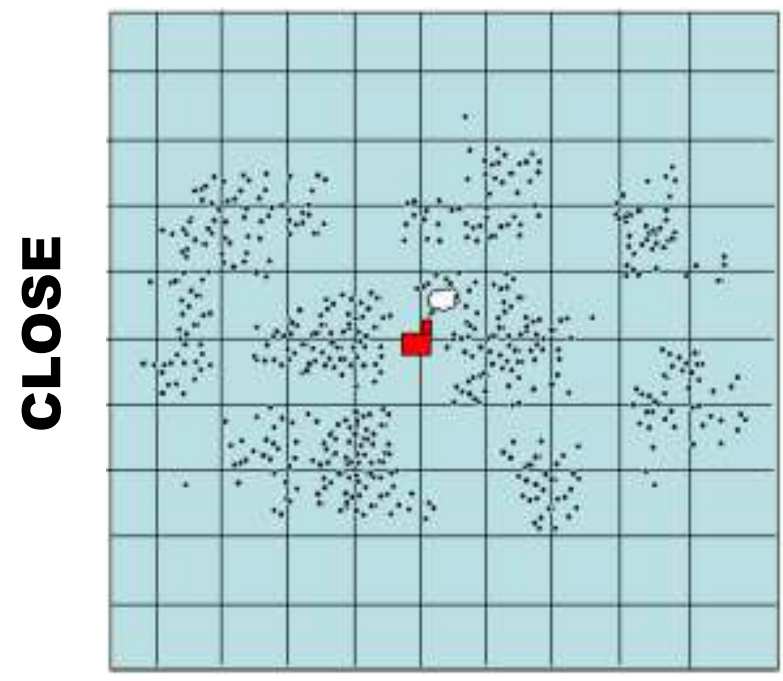

CLUSTERED

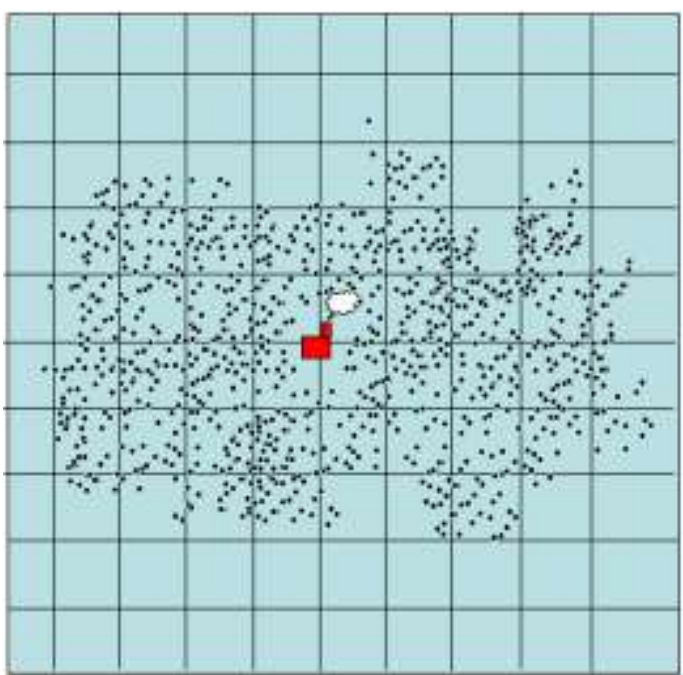

SPREAD

Figure 1. Four scenarios depending on the two factors considered in the experiments 

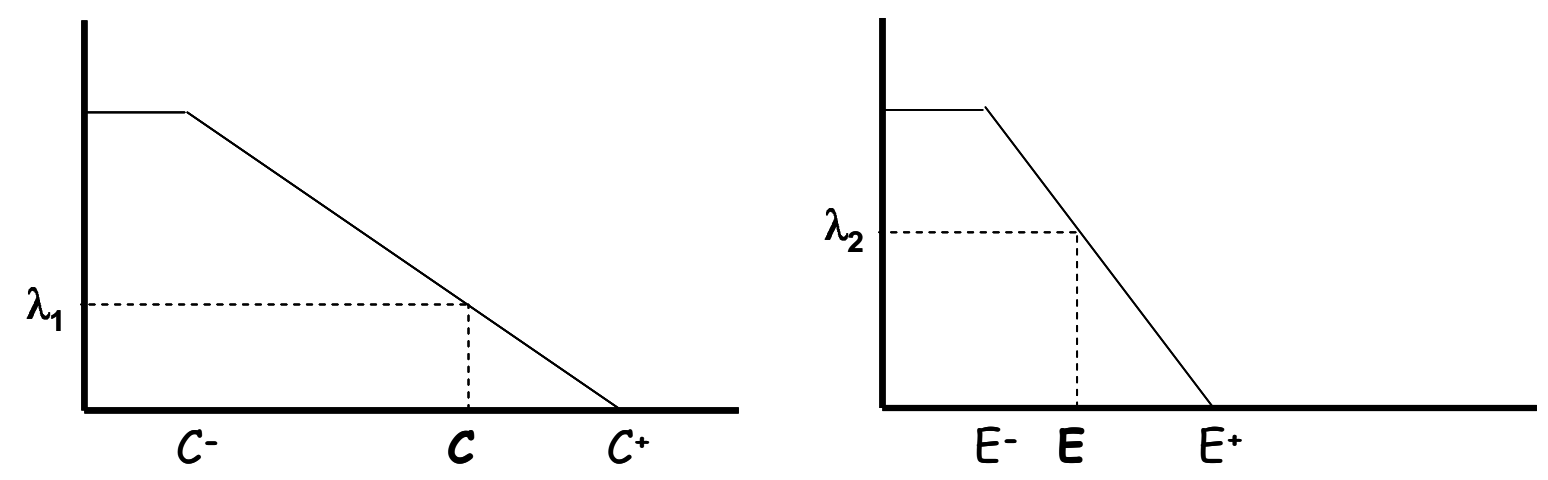

Figure 2. Membership functions for each objective, given some specific cost $\mathrm{C}$ and emissions $\mathrm{E}$.

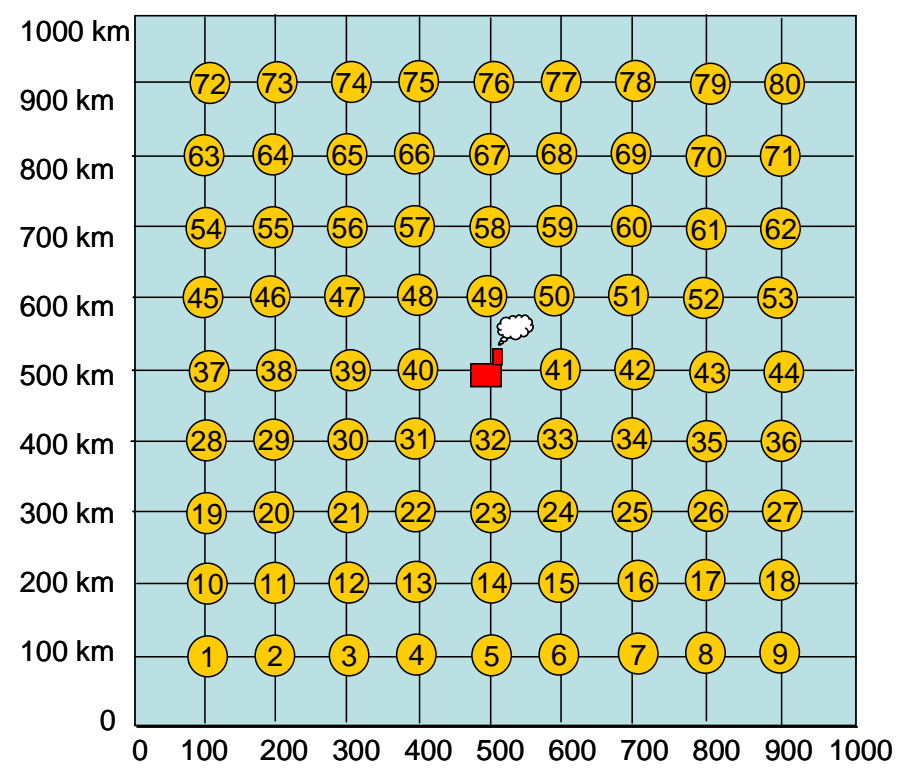

Figure 3. Grid used for all the experiments, with a central plant and 80 potential warehouse locations 


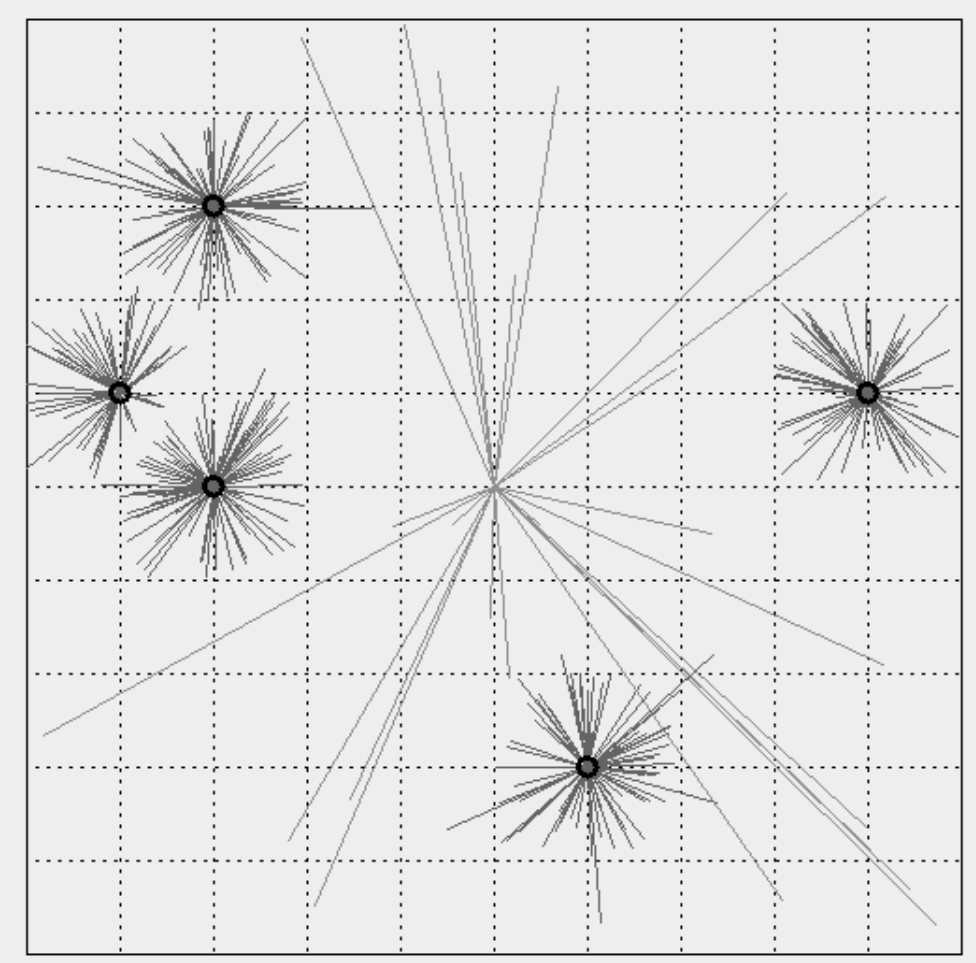

Figure 4. Example of the solution (regarding open warehouses and customers covered by each one and the central plant) given by the model, for a specific "clustered/far" instance 


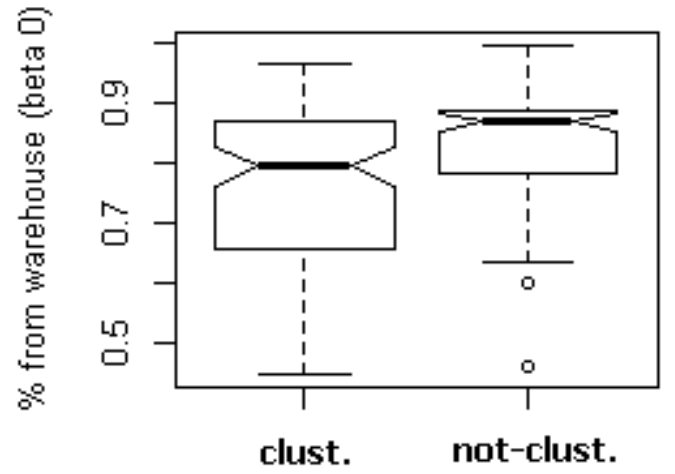

F1

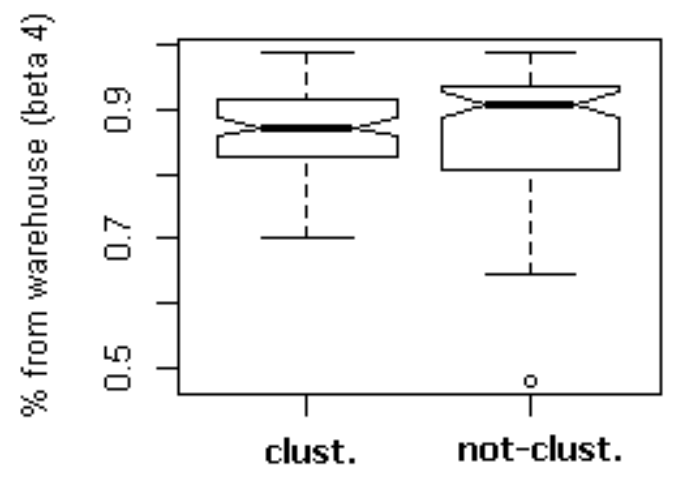

F1

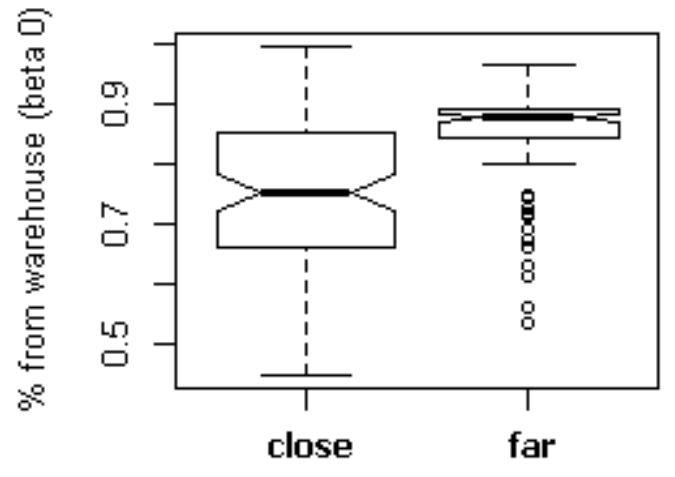

F2

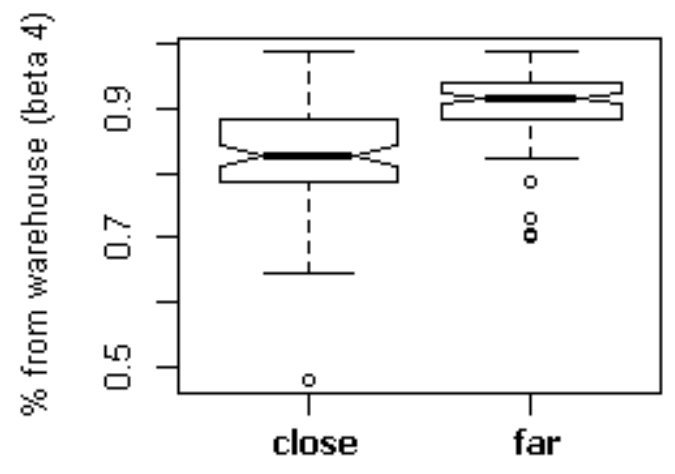

F2

Figure 5. Boxplot for the percentage of material moved through warehouses depending on the two factors (F1:clusterization and F2:closeness) for the extreme values of $\beta$. 


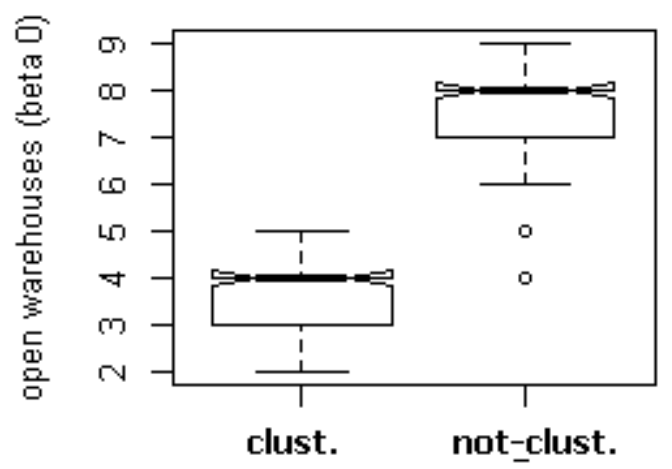

F1

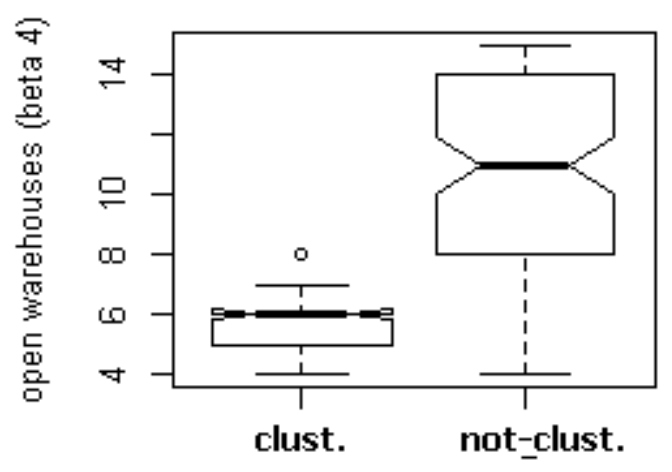

F1

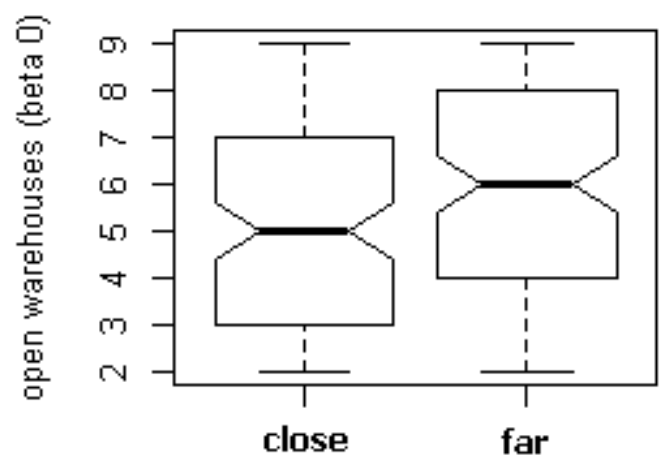

F2

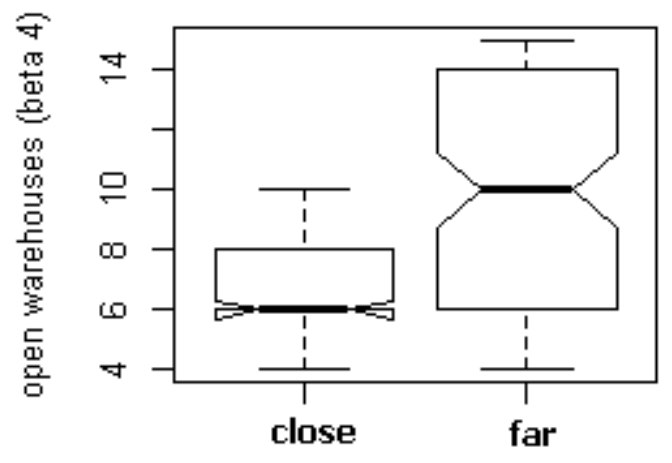

F2

Figure 6. Boxplot of the no. of warehouses open depending on the two factors (F1:clusterization and F2:closeness) for the extreme values of $\beta$. 

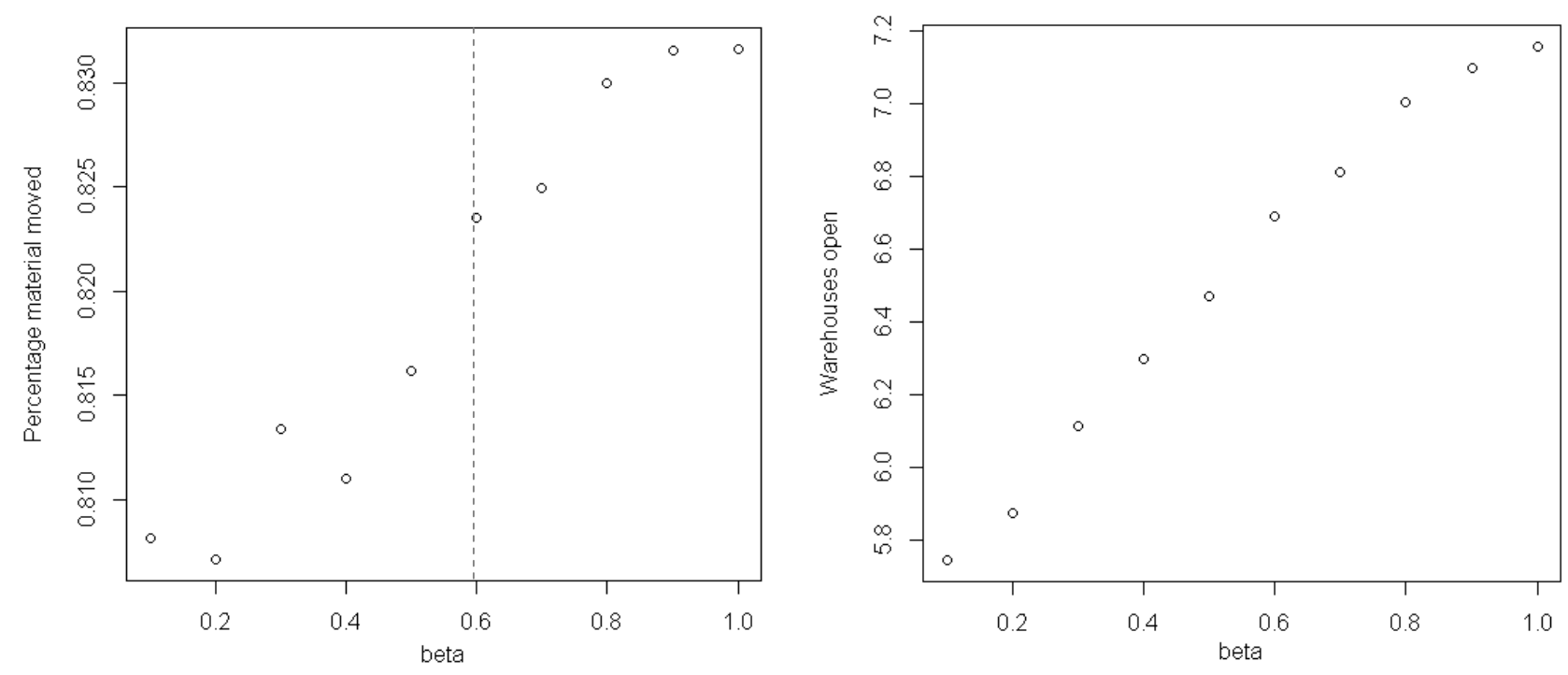

Figure 7. Average percentage of material moved through warehouses (left) and number of open warehouses (right) as a function of $\beta=0.1, . ., 1.0$. 